\title{
A TECHNIQUE FOR REDUCING THE BEAM WIDTH OF THE DOPPLER ULTRASOUND PROBE WITH POTENTIAL APPLICATION FOR ACCURATE LOCATION OF SMALL SUPERFICIAL ARTERIES
}

\author{
Herbert M. Chinyanga ANd John M. SMITH
}

WE PRoposed to use the doppler ultrasound probe as an aid to percutaneous cannulation of the radial artery in infants. However, crystal dimensions of conventional doppler ultrasound probes used for detecting flow in superficial arteries are such that the transmitted beam width is much wider than the artery in which flow is to be detected. This enables flow detection to be easily accomplished without the need for precise positioning of the probe. ${ }^{1}$

In order to use these probes to accurately locate vessels, the width of the ultrasound beam should be equal to that of the artery. This can be achieved either by redesign of the transducer crystal geometry or, alternatively, by limiting the dimensions of the area of contact between the transducer and the patient. This latter change controls the characteristics of the emerging beam, thus improving the ability to locate the vessel precisely. The performance of the modified probe using the latter method is the subject of this paper.

\section{Materials and Methods}

The conventional ultrasound probe and flow detector (Parks Instrument Model 811) ${ }^{1}$ was modified by acoustically coupling a small prism to its transducer surface. This was constructed of plexiglas, with a truncated apex providing a finite contact area $1.3 \mathrm{~mm}$ wide (Figure $\mathrm{l}$ ).

The precision with which a vessel can be located is a function of the width of the beam emerging from the probe. An experimental apparatus allowing this to be measured was designed and assembled. With this, it was possible to compare the performance of different probes. The apparatus illustrated in Figure 2 comprised of a length of silastic tubing simulating a blood

Herbert M. Chinyanga, M.Sc., M.D., F.R.C.P.(C) Staff Anaesthetist, Department of Anaesthesia.

John M. Smith, Ph.D., P.Eng., Director, Department of Medical Engineering.

The Hospital for Sick Children and the University of Toronto, Toronto, Ontario, Canada.

Presented in part at the annual meeting of The Canadian Anaesthetists' Society, Ottawa, June, 1978.

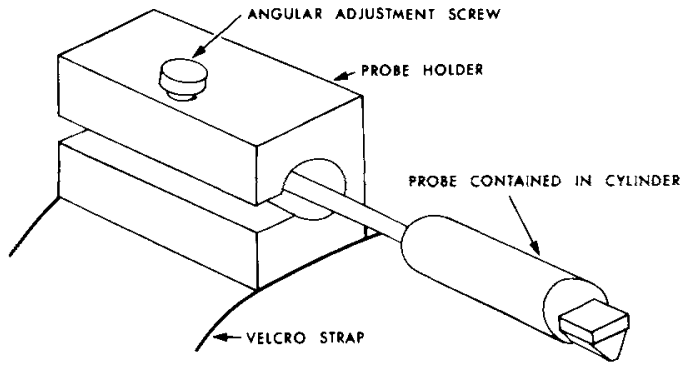

Figure I The modified probe. A prism attached to the underside reduces the contact area and the width of the emerging beam. The probe holder and velcro strap are designed to allow the assembly to be attached to a subject’s wrist.

EXPERIMENTAL SET UP FOR DETECTING FLOW IN TUBES USING ULTRASOUND DOPPLER DEVICE

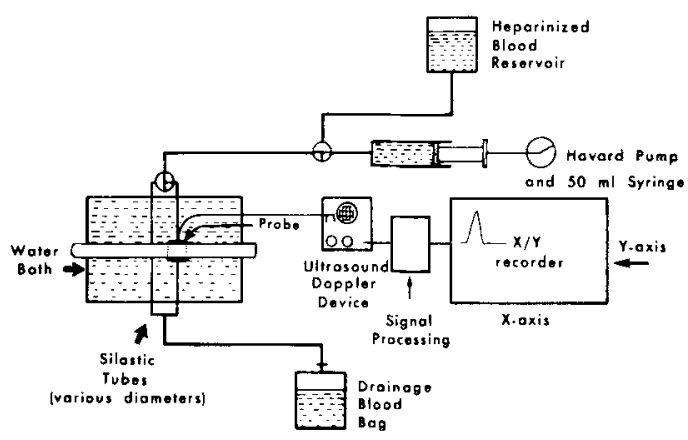

Figure 2 The experimental apparatus. The water bath and ultrasound probe are viewed from above.

vessel, $1.9 \mathrm{~mm} \mathrm{I.D.} \mathrm{and} 2.5$ O.D., supported on a plexiglas plate located beneath the water surface of a test tank. Plumbing connections were arranged so that outdated heparinized blood could be pumped at constant flow from a $50 \mathrm{ml}$ syringe pump through the silastic tube to a collection bag. The Doppler probe was mounted on a horizontal potentiometer arm so that the contact surface of the prism made contact with a thin plexiglas plate located on the surface of the water. The surface of this plexiglas plate was sprayed with silicone antifoam spray (Dow Corning Antifoam A Spray) to produce a fine film which provided the acoustic coupling between the transducer and the water in the bath. The depth from the contact area of the 
BEAM PROFILES

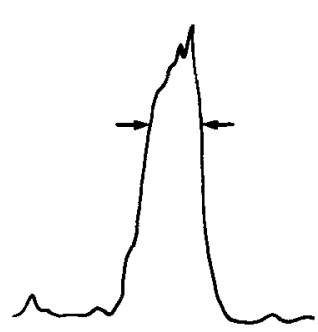

(a)

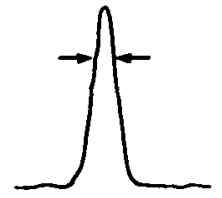

(b)

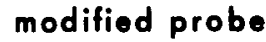

\section{conventional probe}

Figure 3 A comparison between the beam profiles generated using (a) the conventional probe and (b) the modified probe. The depth at which the beam profiles were generated was $2.9 \mathrm{~mm}$. The half power beam widths were 2.6 and $0.9 \mathrm{~mm}$ respectively.

centre line of the silastic tubes could be varied through a distance of $2.9-15.9 \mathrm{~mm}$, altering the depth of the plexiglas plate on which the silastic tube lay. The probe could be moved manually horizontally through a distance of $15 \mathrm{~mm}$ in a direction normal to the silastic tube, while maintaining contact with the plexiglas plate. The potentiometer was connected to a power supply such that a voltage proportional to position was generated as the probe was moved along the arm. The probe was connected to a conventional Doppler ultrasound detector and amplifier. The Doppler output signal, having a frequency related to flow, and an amplitude related to the relative position of the probe and the silastic tubes, was rectified and filtered by signal processing circuitry. The resultant ouput, a signal representing the amplitude of the flow signal, was connected to the $\mathrm{Y}$-axis of an $\mathrm{X}-\mathrm{Y}$ recorder. The displacement voltage was connected to the $\mathrm{X}$-axis, thus allowing a plot of received signal amplitude versus displacement to be generated.

This apparatus allowed beam profiles to be readily recorded and simplified comparisons of the two probes.

The experiment carried out was to study the divergence and width of the ultrasound beam with respect to the distance from the contact area. This was done by measuring the changes in the beam profile at various depths, using the flow in the silastic tube as the beam reflector.

\section{EXPERIMENTAL Results}

Beam width is defined as the width of the beam

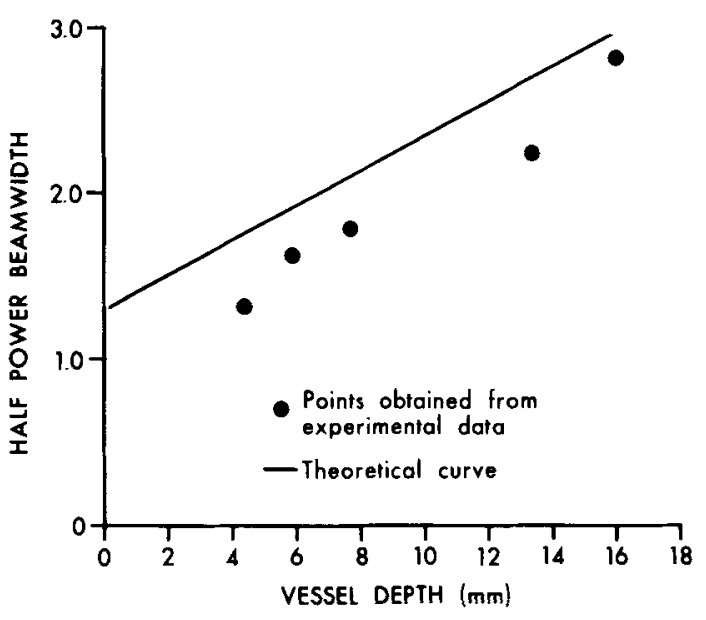

Figure 4 The relationship between beam width and depth. The experimental points were obtained using the apparatus in Figure 2. The theoretical relationship was obtained using an approximate analysis based on the theory of diffraction.

profile at the half power point, corresponding to an output amplitude which is 71 per cent of the maximum. The beam profiles for the conventional and modified probes at a depth of $2.9 \mathrm{~mm}$ are compared in Figure 3. Both profiles were recorded under identical conditions, which resulted in a smaller amplitude from the modified probe. This is primarily due to the reduction in energy reflected to the receiver because of the smaller contact area. The difference in amplitude does not affect the relative beam widths which, in the example given, have a ratio of 2.8:1.

A graphic summary of the results is shown in Figure 4 . These results show a reasonable agreement with an approximate theoretical calculation based on the assumption of Fraunhofer diffraction $^{2}$ from a rectangular aperture illuminated with a plane wave. It is evident that the beam width increases with increasing depth; however, in the region up to a distance of $4 \mathrm{~mm}$ it is close to the width of the contact area. It is in this region that improvement in the precision of vessel location can be expected.

\section{Discussion}

The modified probe used in the experiments described above had a contact area width of $1.3 \mathrm{~mm}$ compared to the $5 \mathrm{~mm}$ width of a conventional probe. Contact area width can be varied to obtain different beam characteristics. Theoretical predictions, using the same technique which resulted in the curve in Figure 4, were made for contact area widths, $0.5,1.0,1.3,3.0$ and $5.0 \mathrm{~mm}$ 


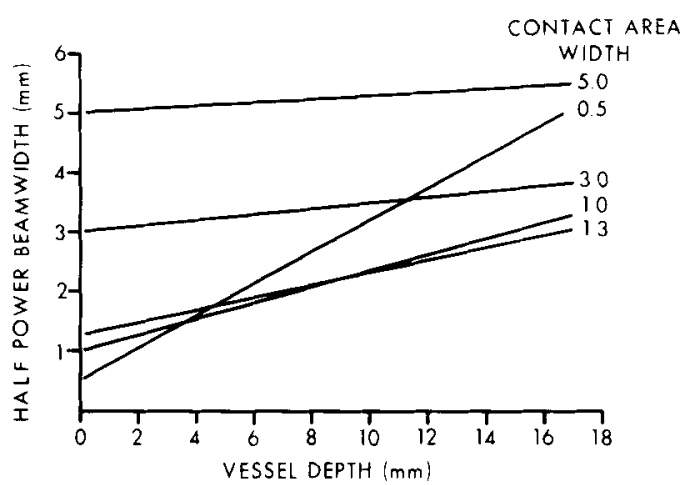

Figure 5 Theoretical relationship between depth and beam width for various contact area widths.

respectively. The results are plotted in Figure 5. As the width increases, the width of the beam in the region close to the probe increases; however, the divergence decreases. Thus the precision with which vessels can be located deteriorates close to the probe but improves at greater depths. Conversely, when the width of the contact area is decreased the beam width close to the probe decreases and the divergence increases resulting in poorer precision at greater depths. Proper choice of contact area width will depend on the region in which precision is required.

The wide variations in the geometry of small arteries allows some degree of flexibility in the choice of contact area width. Based on considerations of typical vessel internal diameters of $1-2 \mathrm{~mm}$ at depths of $5.8 \mathrm{~mm}$, a contact area width of $1.3 \mathrm{~mm}$ was chosen.

Because experimental results obtained with the modified probe demonstrated sufficient promise, clinical trials have been initiated to determine the efficacy of the device as an aid to percutaneous cannulation of the radial artery in infants and small children.

\section{SUMMARY}

A simple technique for reducing the beam width of the Doppler ultrasound probe is described. This is accomplished by attaching a plexiglas prism to the transducer surface of the conventional probe. It reduces the beam width by a ratio of $2.8: 1$. This improves the precision with which the probe is able to locate small superficial arteries.

\section{RÉSUMÉ}

On a modifié une sonde à ultrasons conventionnelle en fixant à la surface du capteur un petit prisme de plexiglas. Le but de cette transformation était de réduire la largeur du faisceau situé près de la surface de contact. En comparant au voisinage de cette surface la divergence et la largeur du faisceau de la sonde conventionnelle avec celles de la sonde modifiée, on a trouvé un rapport de 2.8:1. Cette modification permet donc une meilleure utilisation de la sonde pour localiser les petites artères superficielles de l'enfant dans lesquelles on voudrait insérer une canule.

\section{ACKNOWLEDGEMENTS}

We wish to thank the following members of our two departments for the help they gave at various stages during the preparation of this paper: Mr. E. Zouch, Mrs. S. Sabadin, and Dr. D.J. Steward.

\section{REFERENCES}

1. Operating Manual, Ultrasonic Doppler flow detector. Model 811, p. 1-3, Parks Electronic Laboratories, Beaverton, Oregon, U.S.A.

2. Sears, F.W. Optics, 3rd Ed.. Addison Wesley Chap. 9, pp. 221-252 (1958). 